\title{
1 JURNAL
}

ISSN : 2088 - 5369

\section{Mes 2010 Volume1 Nomor1}

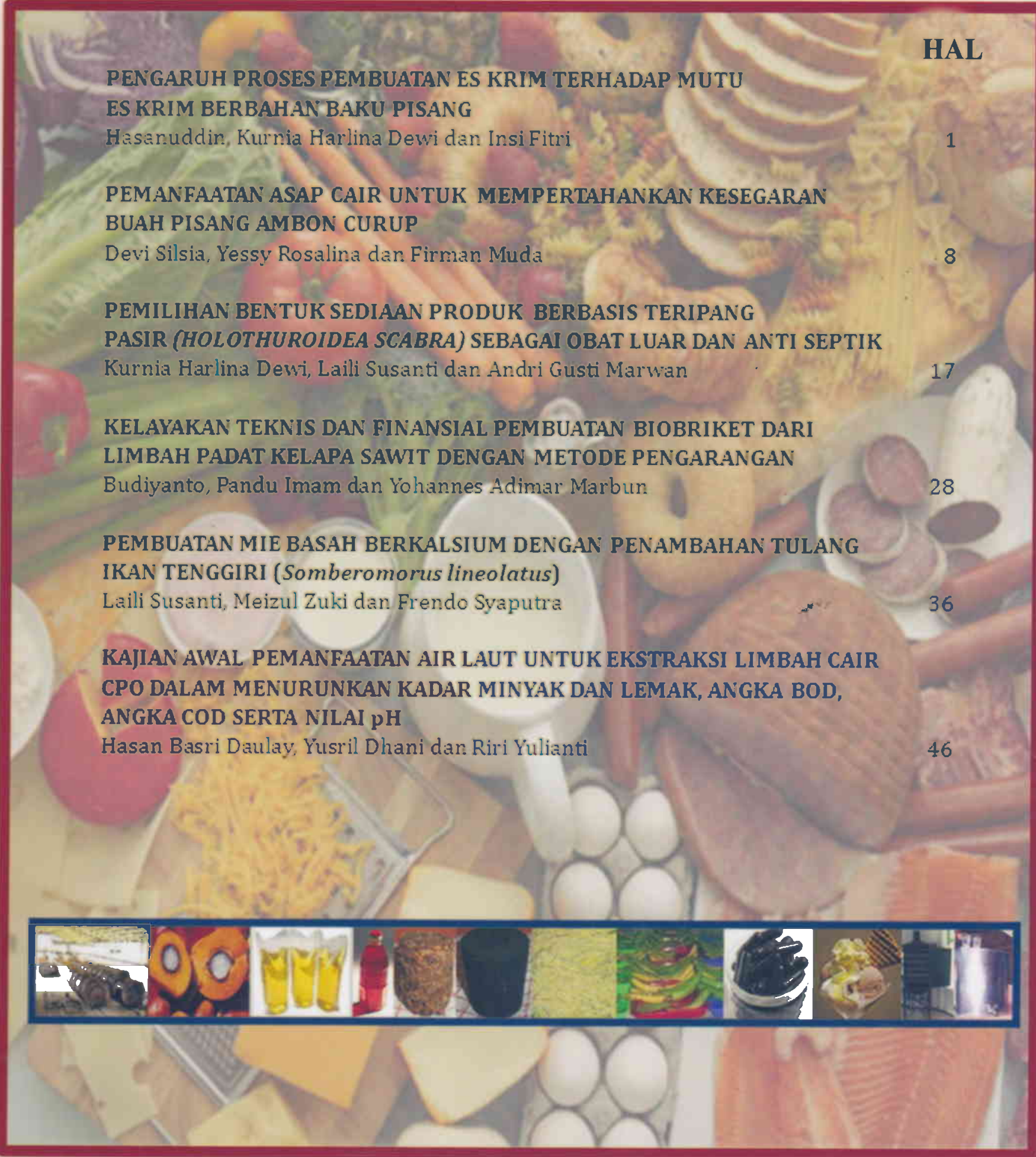




\section{"JURNAL AGROINDUSTRI"}

Media Komunikasi Ilmiah Tentang Agroindustri dan Teknologi Pertanian

\section{TIM REDAKSI}

\section{PENASEHAT / PELINDUNG}

Prof. Dr. Ir. Yuwana, MSc (Dekan Fakultas Pertanian Universitas Bengkulu)

\section{PENANGGUNG JAWAB:}

Dr.Ir.Budiyanto, MSc (Ketua Jur Teknologi Pertanian Fak Pertanian Universitas Bengkulu)

\section{MITRA BESTARI :}

Prof. Dr. Ir. Rindit Pambayun, MP (Jur Teknologi Pertanian, FP Universitas Sriwijaya)

Dr. Ir. Novizar Nazir, MSi (Fakultas Teknologi Pertanian, Universitas Andalas)

Dr. Ir. Sarifah Nurjanah, MSi (Fakultas Teknologi Pertanian, Universitas Pajajaran)

Dr. Ir. Kurnia Harlina Dewi, MSi (Jur Teknologi Pertanian, Universitas Bengkulu)

Ir. Wuri Marsigit, M.App.Sc (Jur Teknologi Pertanian, Universitas Bengkulu)

Ir. Sigit Mujiharjo, M.SAE (Jur Teknologi Pertanian, Universitas Bengkulu)

Ir. Lukman Hidayat, MS (Jur Teknologi Pertanian, Universitas Bengkulu)

\section{EDITOR PELAKSANA :}

Evanila Silvia, STP MS, Ir. Hasanuddin MSc, Drs.Hasan Basti D MS, Ir. Laili Susanti MS, Dra.Devi Silsia MS, Yessy Rosalina STP MS, Drs Syafnil MS, Ir.Meizul Zuki MS, Ir. Hidayat Koto, MSc, Drs.Bosman Sidebang,MS, Ir. Yusril Dhani MS.

ALAMAT : Jurusan Teknologi Pertanian, Fakultas Pertanian Universitas Bengkulu, Gedung U J1. Raya Kandang Limun Bengkulu 38371 A, Telp. 0736-211770 Pesawat 214, E-mail : agroindustriunib@yahoo.com 


\title{
KELAYAKAN TEKNIS DAN FINANSIAL PEMBUATAN BIOBRIKET DARI LIMBAH PADAT KELAPA SAWIT DENGAN METODE PENGARANGAN
}

\author{
Budiyanto, Pandu Imam dan Yohannes Adimar Marbun \\ Program Studi Teknologi Industri Pertanian, Jurusan Teknologi Pertanian \\ Fakultas Pertanian Universitas bengkulu
}

\begin{abstract}
This research was conducted at the Laboratory of Agricultural Technology, University of Bengkulu and Laboratory of PT Sucofindo Bengkulu, from May until August 2009. This study compared three types of biobriquettes such as the biobriquettes made of shell charcoal, coal-mixed TTKS charcoal biobriquettes, and coal-mixed TKKS charcoal with carbonized-coal briquettes. The results showed that, technically, biobriquettes has cylindrical dimension with a diameter of $4.5 \mathrm{~cm}$, height $7 \mathrm{~cm}$, lower hole diameter $1.5 \mathrm{~cm}$, and upper hole diameter $1.2 \mathrm{~cm}$. Biobriquette made of TKKS charcoal is very feasible to use as used as a fuel in compare to carbonized-coal briquettes, since TKKS charcoal biobriquette contains 7, $3 \%$ water and the average calorific value of $6141 \mathrm{kcal} / \mathrm{kg}$. Financially, the manufacturing on these three types of palm oil waste briquettes is very feasible because it has $\mathrm{R} / \mathrm{C}$ value $>1$. However, if these three types compared, coal-mixed TTKS charcoal biobriquettes is preferable because it has $\mathrm{R} / \mathrm{C}$ value 1,78 with break-evenpoint (BEP) $24.468 \mathrm{~kg} /$ year, which is better than biobriquettes made of TKKS charcoal and shell charcoal.
\end{abstract}

\section{PENDAHULUAN}

Seringnya terjadi kelangkaan Bahan Bakar Minyak (BBM) disebabkan oleh banyak faktor diantaranya permintaan BBM semakin meningkat, sementara cadangan minyak bumi justru semakin menipis. Menanggapi fakta tersebut dan efek yang ditimbulkan akibat kelangkaan BBM, pemerintah sangat serius menanggapi permasalahan tersebut, hal ini terbukti dengan diterbitkannya peraturan presiden no 5/2006 tentang kebijakan energi nasional dan intrusi presiden no 1/2006 tentang penyediaan dan pemanfaatan bahan bakar nabati (biofuel) sebagai bahan bakar lain (Fokus, 2008).

Secara nasional terdapat sekitar 205 Pabrik Kelapa Sawit (PKS) di Indonesia dengan perkiraan produksi Tandan Buah Segar (TBS) tahun 2004 diperkirakan mencapai 53,8 juta ton, maka akan dihasilkan beberapa limbah padat organik berupa Tandan Kosong Kelapa Sawit (TKKS) sebesar 12,4 juta ton atau sekitar 23\% (Hadjar, D. G, 2006) dan cangkang sawit sebesar 3,9 juta ton atau 7,28\%. Provinsi Bengkulu terdapat lebih dari 10 Pabrik Kelapa Sawit dengan perkiraan produksi Tandan Buah Segar (TBS) tahun 2006 mencapai 851.821,17 ton maka akan dihasilkan Tandan Kosong Kelapa Sawit sebesar 212.955,25 ton dan cangkang sawit sebesar 62.012,56 ton (Anonim, 2007). Melihat kondisi tersebut, sudah selayaknya kelangkaan BBM di atasi dengan mencari bahan bakar alternatif yang bisa diperbarui (renewable), diantaranya pemanfaatan TKKS dan cangkang kelapa sawit menjadi briket.

Briket adalah suatu padatan dari bahan mudah terbakar yang digunakan 
sebagai bahan bakar yang digunakan untuk menghasilkan api (Wikipedia, 2008). Beberapa tipe briket yaitu briket batu bara dan briket biomassa. Briket biomassa (biobriket) merupakan bahan bakar yang berwujud padat dan berasal dari sisa-sisa bahan organik yang telah mengalami proses pemampatan dengan daya tekan tertentu (Hambali, 2007). Salah satu biobriket yang berpotensi untuk diolah menjadi briket adalah cangkang kelapa sawit dan tandan kosong kelapa sawit (TKKS) yang merupakan limbah dari pabrik pengolahan kelapa sawit.

Dalam realisasinya pembuatan biobriket dari cangkang sawit dan TKKS terdapat dua metode yaitu metode pengarangan dan tanpa pengarangan. Metode pengarangan dapat menurunkan zat-zat terbang (Volatil) yang terkandung pada biobriket serendah mungkin sehingga produk akhirnya tidak berbau dan berasap. Biobriket ini sangat cocok digunakan untuk keperluan rumah tangga serta lebih aman dalam penggunaannya (Anonim, 2005 dalam Lusia, 2008).

Penelitian-penelitian mengenai biobriket cangkang kelapa sawit dan TKKS telah dilakukan dalam usaha menjadikannya sebagai bahan bakar rumah tangga, seperti pembuatan biobriket dari TTKS dengan pengarangan oleh Lusia (2008), pembuatan biobriket dari cangkang sawit dan batubara dengan pengarangan oleh Sari (2007)) dan pembuatan biobriket dari cangkang sawit pengarangan dengan perekat tar oleh Siska (2009). Namun penelitianpenelitian tersebut baru mengkaji karakeristik salah satu jenis biobriket saja melalui beberapa kombinasi perlakuan. Penelitian mengenai beberapa jenis biobriket secara bersamaan untuk mencari jenis biobriket yang terbaik belum dilakukan.

Berdasarkan beberapa masalah yang telah diuraikan diatas, maka perlu dilakukan penelitian terhadap beberapa jenis biobriket sehingga diperoleh hasil biobriket yang terbaik untuk dikembangkan sebagai pengganti bahan bakar rumah tangga.

Selain aspek teknis, juga dilakukan analisis finansial pada proses pembuatan briket. Analisis finansial meliputi analisis biaya (biaya tetap, biaya variabel, biaya total) pembuatan briket, analsisis titik impas (BEP), dan analisis R/C.

Tujuan dari penelitian ini, yaitu:

1. Mengkaji kelayakan teknis biobriket dari limbah padat kelapa sawit dengan metode pengarangan seperti: dimensi biobriket, kadar air, kadar abu, kadar zat terbang, kadar karbon, nilai kalori, Smoke Sensory Test (SST) dan kinerja biobriket sebagai bahan bakar alternatif \{ Water Boiling Test (WBT), Control CookingTest (CCT) \}.

2. Mengkaji kelayakan Finansial usaha pembuatan biobriket sebagai bahan bakar alternatif dalam skala kecil.

\section{METODOLOGI PENELITIAN}

\section{Waktu dan Tempat Penelitian}

Penelitian dilaksanakan pada bulan Mei - Agustus 2009 di Laboratorium Teknologi Pertanian Fakultas Pertanian Universitas Bengkulu dan Laboratorium PT Sucofindo Bengkulu.

\section{Alat dan Bahan penelitian}

Peralatan yang digunakan : drum pengarangan, pencetak briket, kompor briket, kompor minyak tanah, nampah, stopwatch, timbangan, parang, ember, panci, korek api, alat penggerus, baskom, sendok makan, dandang, gelas ukur, ATK, lembar pengujian.

Bahan-bahan yang digunakan adalah cangkang kelapa sawit, TKKS, tepung kanji, air, beras, minyak tanah. 


\section{Variabel Pengamatan}

Variabel yang diamati: dimensi biobriket, kadar air, kadar abu, kadar zat terbang, kadar karbon, nilai kalori, Smoke Sensory Test (SST) dan kemampuan sebagai bahan bakar \{Water Boiling Test (WBT), Control CookingTest (CCT) \}dan analisa kelayakan finansial dalam skala laboratorium.

\section{Pembuatan Biobriket}

Pembuatan beberapa biobriket dengan metode pengarangan, yaitu:

1) Biobriket A : Pembuatan biobriket arang dari cangkang kelapa sawit (modifikasi dari Sari, 2007).

2) Biobriket B : Pembuatan biobriket arang dari TKKS (60\%) yang campuran dengan batubara (30\%) (modifikasi dari Sari, 2007).

3) Biobriket C : Pembuatan biobriket arang dari tandan kosong kelapa sawit (tkks) (modifikasi dari Lusia, 2008).

4) Penentuan spesifikasi biobriket seperti dimensi, kadar air, kadar abu, kadar zat terbang, kadar karbon dan nilai kalor.

\section{Tahapan Penelitian}

\section{Kelayakan Teknis Pembuatan}

\section{Biobriket}

1) Kadar Air, Kadar Abu, Kadar Zat Terbang, Kadar Karbon dan Nilai Kalor.

Kadar air, kadar abu, kadar zat terbang, kadar karbon dan nilai kalor dianalisa secara otomatis di Laboratorium PT.Sucofindo Bengkulu.

\section{2) Smoke Sensory Test (SST)}

SST merupakan pengujian terhadap asap yang dihasilkan dari hasil pembakaran briket. Asap adalah suspensi partikel kecil d udara (aerosol) yang berasal dari pembakaran tak sempurna dari suatu bahan bakar. Pengamatan asap yang dihasilkan oleh tiga jenis biobriket dengan penilaian menggunakan indera penglihatan berupa tingkat kesukaan panelis terhadap asap yang dihasilkan dari pembakaran.

3) Kinerja Biobriket Sebagai bahan Bakar

a) Water Boiling Test (WBT), yaitu uji kemampuan biobriket dalam mendidihkan air. Air yang akan digunakan dalam penelitian ini adalah sebanyak 3 liter. Caranya ialah dengan mencatat waktu hingga air mendidih $100^{\circ} \mathrm{C}$. Pengujian dilakukan sebanyak 3 kali ulangan untuk masingmasing jenis biobriket. Data yang dihasilkan lalu dibandingkan dengan waktu untuk memasak air menggunakan kompor minyak tanah.

b) Control Cooking Test (CCT) CCT merupakan jenis pengujian kemampuan biobriket untuk memasak jenis makanan tertentu. biobriket akan diuji kemampuannya untuk memasak nasi. Pengujian dilakukan sebanyak 3 kali ulangan untuk masing-masing jenis biobriket. Data yang dihasilkan lalu dibandingkan dengan waktu untuk memasak nasi menggunakan kompor minyak tanah.

\section{Kelayakan Finansial Pembuatan Biobriket}

Kelayakan finansial pembuatan biobriket dilakukan dalam skala kecil. Adapun variabel finansial yang akan dianalisis ialah:

- Total Biaya Pembuatan Biobriket (Total Cost)

- Break Even Point (BEP)

- $R / C$ Ratio 


\section{Analisa Data}

Data dianalisis secara deskriptif kuantitatif. Hasil pengukuran kadar air, kadar abu, kadar zat terbang, nilai kalori, Smoke Sensory Test dan kinerja biobriket sebagai bahan bakar alternatif (Water Boiling Test dan Control CookingTest) disajikan dalam bentuk grafik dan dibandingkan dengan minyak tanah.

\section{HASIL DAN PEMBAHASAN}

\section{Dimensi Biobriket}

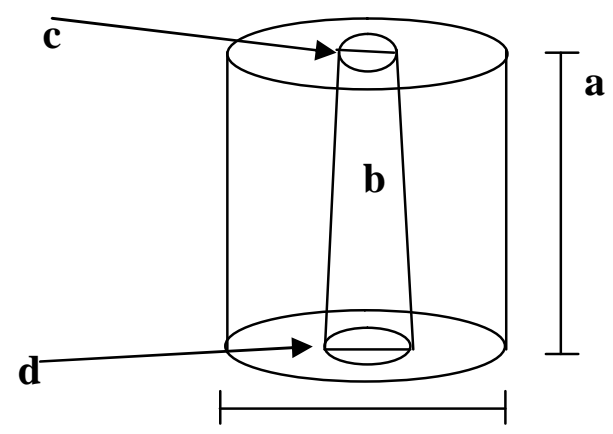

Gambar 1. Dimensi Biobriket

Ket:

a. Tinggi Biobriket : $7 \mathrm{~cm}$

b. Diameter Biobriket : $4,5 \mathrm{~cm}$

c. Diameter Lubang Atas : 1,2 cm

d. Diameter Lubang Bawah : 1,5 cm

Tabel 1. Kelayakan Teknis Biobriket Dari Limbah Padat Kelapa Sawit Dengan Metode Pengarangan.

\begin{tabular}{llcccc}
\hline No & Variabel Pengamatan & $\begin{array}{c}\text { Karakteristik } \\
\text { Briket Arang } \\
\text { Cangkang }\end{array}$ & $\begin{array}{c}\text { Biobriket } \\
\text { A }\end{array}$ & $\begin{array}{c}\text { Biobriket } \\
\text { B }\end{array}$ & $\begin{array}{c}\text { Biobriket } \\
\text { C }\end{array}$ \\
\hline 1. & Kadar Air $(\%)$ & 8,47 & $10,95^{* * *}$ & $7,71^{* *}$ & $7,35^{*}$ \\
2. & Kadar Abu $(\%)$ & 9,65 & $17,82^{* * *}$ & $7,94^{* * *}$ & $3,42^{*}$ \\
3. & Kadar Zat Terbang $(\%)$ & 21,20 & $23,50 *$ & $28,90^{* *}$ & $32,56^{* * *}$ \\
4. & Kadar Karbon $(\%)$ & 69,25 & $47,72^{* * *}$ & $55,45^{* *}$ & $56,67 *$ \\
5. & Nilai Kalor $(\mathrm{Kkal} / \mathrm{Kg})$ & 6.600 & $4.962^{* * *}$ & $5.874^{* *}$ & $6.141^{*}$ \\
\hline
\end{tabular}

Sumber Gunadi et al. (2005) dan Sucofindo (2009).

Keterangan:

* = Peringkat Pertama

$* *$ = Peringkat Kedua

$* * *=$ Peringkat Ketiga

Biobriket $\mathrm{A}=$ Biobriket Arang Cangkang

Biobriket $\mathrm{B}=$ Biobriket Arang TKKS Campur Batubara

Biobriket $\mathrm{C}=$ Biobriket Arang TKKS 
Tabel 2. Informasi Tambahan Kelayakan Teknis Biobriket Dari Limbah Padat Kelapa Sawit Dengan Metode Pengarangan.

\begin{tabular}{|c|c|c|c|c|c|c|}
\hline No. & Variabel Pengam & $\tan$ & Kontrol & $\begin{array}{l}\text { Biobriket } \\
\text { A }\end{array}$ & $\begin{array}{l}\text { Biobriket } \\
\text { B }\end{array}$ & $\begin{array}{l}\text { Biobriket } \\
\text { C }\end{array}$ \\
\hline 1. & Smoke Sensory Test & SST) & 4,38 & $3,45^{*}$ & $3,04 * *$ & $2,69 * * *$ \\
\hline 2. & Waktu Penyalaan (M & enit) & 1,42 & $7,37 * *$ & $10,51 * * *$ & $5,93 *$ \\
\hline 3. & $\begin{array}{l}\text { Waktu Pembakaran } \\
\text { Nyala; Waktu Bara) }\end{array}$ & $\begin{array}{l}\text { Waktu } \\
\text { Menit) }\end{array}$ & - & $\begin{array}{l}(30,07 \\
44,92)^{*}\end{array}$ & $\begin{array}{c}(22,33 \\
54,58)^{* * *}\end{array}$ & $\begin{array}{c}(40,25 \\
64,22)^{* *}\end{array}$ \\
\hline 4. & $\begin{array}{l}\text { Waktu Memasak } \\
\text { (Menit)/WBT }\end{array}$ & Air & 14,21 & $20,54 *$ & $47,34 * * *$ & $25,18 * *$ \\
\hline 5. & $\begin{array}{l}\text { Konsumsi } \\
\text { Bakar/WBT (Gram) }\end{array}$ & Bahan & 106,25 & $211,47 * * *$ & $204,97 * *$ & $200,6^{*}$ \\
\hline 6. & $\begin{array}{l}\text { Waktu Memasak } \\
\text { (Menit)/CCT }\end{array}$ & Nasi & 32,17 & $36,31 *$ & $39,37 * * *$ & $37,06 * *$ \\
\hline 7. & $\begin{array}{l}\text { Konsumsi Bahan } \\
\text { (Menit)/CCT }\end{array}$ & Bakar & 83,66 & $199,57 * *$ & $222,65 * * *$ & $188 *$ \\
\hline
\end{tabular}

Keterangan:

* = Peringkat Pertama

$* *$ = Peringkat Kedua

*** = Peringkat Ketiga

Biobriket $\mathrm{A}=$ Biobriket Arang Cangkang

Biobriket $\mathrm{B}=$ Biobriket Arang TKKS Campur Batubara

Biobriket $\mathrm{C}=$ Biobriket Arang TKKS

Analisis Finansial Biobriket

\section{Skala Kecil Dengan Produksi}

Biobriket 50 Kg/Hari

Dalam perhitungan analisis

kelayakan usaha ini, perlu menggunakan asumsi. Adapun asumsi yang digunakan dalam usaha produksi Biobriket dari limbah padat kelapa sawit adalah sebagai berikut.

1. Produksi biobriket bersifat skala kecil dengan tenaga manusia (manpower) menjadi kekuatan utama.

2. Tenaga kerja dihitung harian dengan 1 hari orang kerja (HOK) lamanya 8 jam.

3. Jumlah produksi $50 \mathrm{~kg} / \mathrm{hari}$ dengan rendemen arang cangkang 50\% dan rendemen arang TKKS $40 \%$.

4. Harga jual biobriket di pasaran diasumsikan Rp 10.000/kg.

5. Bunga bank pertahunnya $14 \%$. 
Tabel 3. Analisis Finansial Pembuatan Biobriket Dari Limbah Padat Kelapa Sawit Skala Kecil Dengan Produksi Biobriket 50 Kg/Hari.

\begin{tabular}{ccccccc}
\hline No. & $\begin{array}{c}\text { Jenis } \\
\text { Biobriket }\end{array}$ & $\begin{array}{c}\text { Fix Cost } \\
(\mathrm{FS}) \\
(\mathrm{Rp} / \mathrm{Th})\end{array}$ & $\begin{array}{c}\text { Variable } \\
\text { Cost } \\
(\mathrm{VC}) \\
(\mathrm{Rp} / \mathrm{Th})\end{array}$ & $\begin{array}{c}\text { Total Cost } \\
(\mathrm{TC}) \\
(\mathrm{Rp} / \mathrm{Th})\end{array}$ & $\begin{array}{c}\text { Break Even } \\
\text { Point } \\
(\text { BEP }) \\
(\text { Kg/Th })\end{array}$ & $\begin{array}{c}\text { Revenue } \\
\text { Cost Ratio } \\
(\mathrm{R} / \mathrm{C} \\
\text { Ratio })\end{array}$ \\
\hline 1. & Biobriket A & 54.220 .000 & 50.710 .000 & 104.930 .000 & 819,03 & $1,43^{* *}$ \\
2. & Biobriket B & 54.220 .000 & 51.025 .000 & 105.245 .000 & 821,51 & $1,42^{* * *}$ \\
3. & Biobriket C & 54.220 .000 & 50.035 .000 & 104.255 .000 & 812,89 & $1,44^{*}$ \\
\hline
\end{tabular}

Keterangan:

* = Peringkat Pertama

** $=$ Peringkat Kedua

$* * *$ = Peringkat Ketiga

Biobriket $\mathrm{A}=$ Biobriket Arang Cangkang

Biobriket $\mathrm{B}=$ Biobriket Arang TKKS Campur Batubara

Biobriket $\mathrm{C}=$ Biobriket Arang TKKS

\section{Skala Kecil Dengan Produksi}

Biobriket $250 \mathrm{Kg} / \mathrm{Hari}$

Dalam perhitungan analisis

kelayakan usaha ini, digunakan beberapa asumsi yaitu :

1. Produksi biobriket bersifat skala kecil.

2. Tenaga kerja dihitung harian dengan 1 hari orang kerja (HOK) lamanya 8 jam.
3. Jumlah produksi $500 \mathrm{~kg} /$ hari dengan rendemen arang cangkang 50\% dan rendemen arang TKKS $40 \%$.

4. Harga jual biobriket di pasaran diasumsikan Rp 4.000/kg.

5. Bunga bank pertahunnya yaitu $16 \%$.

Tabel 4. Analisis Finansial Pembuatan Biobriket Dari Limbah Padat Kelapa Sawit Skala Kecil Dengan Produksi $250 \mathrm{Kg} / \mathrm{Hari}$.

\begin{tabular}{ccccccc}
\hline No. & $\begin{array}{c}\text { Jenis } \\
\text { Biobriket }\end{array}$ & $\begin{array}{c}\text { Fix Cost } \\
(\mathrm{FS}) \\
(\mathrm{Rp} / \mathrm{Th})\end{array}$ & $\begin{array}{c}\text { Variable } \\
\text { Cost } \\
(\mathrm{VC}) \\
(\mathrm{Rp} / \mathrm{Th})\end{array}$ & $\begin{array}{c}\text { Total Cost } \\
(\mathrm{TC}) \\
(\mathrm{Rp} / \mathrm{Th})\end{array}$ & $\begin{array}{c}\text { Break Even } \\
\text { Point } \\
(\text { BEP }) \\
(\text { Kg/Th })\end{array}$ & $\begin{array}{c}\text { Revenue } \\
\text { Cost Ratio } \\
(R / C \\
\text { Ratio })\end{array}$ \\
\hline 1. & Biobriket A & 63.626 .000 & 109.462 .000 & 173.088 .000 & 25.046 & $1,73^{* * *}$ \\
2. & Biobriket B & 63.626 .000 & 104.962 .000 & 168.588 .000 & 24.468 & $1,78^{*}$ \\
3. & Biobriket C & 63.626 .000 & 106.087 .000 & 169.713 .000 & 24.608 & $1,77^{* *}$ \\
\hline
\end{tabular}

Keterangan:

* $\quad=$ Peringkat Pertama

** = Peringkat Kedua

*** = Peringkat Ketiga

Biobriket $A=$ Biobriket Arang Cangkang

Biobriket $B=$ Biobriket Arang TKKS Campur Batubara

Biobriket $C=$ Biobriket Arang TKKS 


\section{KESIMPULAN}

Berdasarkan penelitian yang telah dilakukan maka dapat ditarik kesimpulan

1. Secara teknis pembuatan biobriket $B$ (arang TKKS campur batubara) dan biobriket C (arang TKKS) layak berdasarkan spesifikasi briket arang cangkang. Hal ini disebabkan karena biobriket B (arang TKKS campur batubara) dan biobriket $\mathrm{C}$ (arang TKKS) sudah memenuhi tiga variabel pengamatan (kadar air, kadar abu dan kadar karbon) dari lima variabel pengamatan (kadar air, kadar abu, kadar zat terbang, kadar karbon dan nilai kalor) briket arang cangkang.

2. Sedangkan untuk pembuatan biobriket A (arang cangkang) secara teknis masih belum layak karena hanya memenuhi satu variabel pengamatan (kadar karbon) dari lima variabel pengamatan (kadar air, kadar abu, kadar zat terbang, kadar karbon dan nilai kalor) briket arang cangkang.

3. Secara finansial dalam pembuatan biobriket dari limbah padat kelapa sawit dengan metode pengarangan dalam skala kecil dengan jumlah produksi perharinya $50 \mathrm{~kg}$ masih tidak layak diusahakan karena harga yang masih terlalu mahal yaitu $\mathrm{Rp}$ $10.000 / \mathrm{kg}$ dibanding harga minyak tanah tanpa subsidi yaitu $\mathrm{Rp}$ 6.000/liter.

4. Bila produksi ditingkatkan menjadi $250 \mathrm{~kg} / \mathrm{hari}$ maka, pembuatan biobriket dari limbah padat kelapa sawit menjadi layak untuk diusahakan karena harga biobriket perkilogramnya dapat diturunkan menjadi Rp 4.000 sehingga dapat bersaing dengan harga minyak tanah tanpa subsidi yaitu Rp 6.000/liter.

\section{SARAN}

Berdasarkan hasil maka disarankan beberapa hal sebagai berikut :

1. Karena bentuk TKKS yang masih cukup besar dan sulit untuk dikarbonisasi maka, sebaiknya TKKS dibelah membusur sebelum dilakukan proses karbonisasi.

2. Karena waktu penyalaan biobriket yang masih lama (tercepat biobriket $B$ yaitu 5,93 menit), maka sebaiknya biobriket yang telah dijemur diberi lapisan penyala.

3. Perlu dilakukan penelitian lebih lanjut untuk skala sedang dan skala industri dalam penyediaan energi alternatif dan meningkatkan nilai tambah PMKS.

\section{DAFTAR PUSTAKA}

Anonim. 2005. Briket Batubara Sebagai alternative Pengganti Minyak Tanah.

http://www.beritaiptek.com/zberita -beritaiptek-2005-11-21-Briket-

Batubara-Sebagai....artikel. 21November 2005.

Anonim. 2007. Bengkulu Dalam Angka 2006. BPS Propinsi Bengkulu. Bengkulu.

Siska, A. 2009. Kajian Pemanfaatan Fraksi Berat Hasil Pirolisis Cangkang Sawit (TAR) Sebagai Bahan Perekat Dalam Proses Pembuatan Briket Arang Cangkang Sawit. Skripsi Fakultas Pertanian. Universitas Bengkulu. (Skripsi tidak dipublikasikan).

Fokus. 2008. Biofuel Menyimpan Harapan baru. Fokus. Jakarta: PLN (Persero).

Hambali, E. 2007. Teknologi Bioindustri. Argomedia. Jakarta. 
Lusia. 2008. Pembuatan Briket Dengan Komposisi Limbah Cair Cpo (Crude Palm Oil) Dan Arang Tandan Kosong Kelapa Sawit. Skripsi Fakultas Pertanian. Universitas Bengkulu. (Skripsi tidak dipublikasikan).

Wikipedia. $2008 . \quad$ Briquette. http:/en.wikipedia.org/wiki/briq uette. 